\title{
Rainfall intensity characteristics at coastal and high altitude stations in Kerala
}

\author{
V Sasi Kumar, S Sampath, P V S S K Vinayak and R Harikumar \\ Atmospheric Sciences Division, Centre for Earth Science Studies, Thiruvananthapuram 695031 , India.
}

\begin{abstract}
Rainfall intensities measured at a few stations in Kerala during 2001-2005 using a disdrometer were found to be in reasonable agreement with the total rainfall measured using a manual rain gauge. The temporal distributions of rainfall intensity at different places and during different months show that rainfall is of low intensity $(<10 \mathrm{~mm} / \mathrm{hr}), 65 \%$ to $90 \%$ of the time. This could be an indication of the relative prevalence of stratiform and cumuliform clouds. Rainfall was of intensity $<5 \mathrm{~mm} / \mathrm{hr}$ for more than $95 \%$ of the time in Kochi in July 2002, which was a month seriously deficient in rainfall, indicating that the deficiency was probably due to the relative absence of cumuliform clouds. Cumulative distribution graphs are also plotted and fitted with the Weibull distribution. The fit parameters do not appear to have any consistent pattern. The higher intensities also contributed significantly to total rainfall most of the time, except in Munnar (a hill station). In this analysis also, the rainfall in Kochi in July 2002 was found to have less presence of high intensities. This supports the hypothesis that the rainfall deficiency was probably caused by the absence of conditions that favoured the formation of cumuliform clouds.
\end{abstract}

\section{Introduction}

The measurement of rainfall intensity is of importance in many respects. These data are needed, for instance, in the modelling of soil erosion (using models like RUSLE or WEPP). These models usually require a time series of rainfall intensity with moderate to high time resolution. A knowledge of rainfall intensities that can be expected to help design structures like culverts so that they can handle the storm waters during heavy rainfall. Rainfall intensity is also important to understand the rate of recharge of the water table and to estimate runoff. Apart from these, the effects of climate change are now making rainfall intensity measurements even more important. For instance, Gordon et al (1992) report results from a model that point to increase in rainfall intensity due to enhanced greenhouse effect. A study in Australia by Haylock and Nicholls (2000) showed an increase in the total rainfall and number of rainy days in the northern and southern regions and a decrease in the western and southwestern regions. Their study implied a significant change in the number of heavy events in the southwest and a significant change in only the number of lighter events in the north.

Most of the rainfall measurements in India are limited to daily rainfall, with only a relatively few stations recording rain gauges that can give hourly rainfall values. Rainfall data have been used in many studies (for instance, Ananthakrishnan et al 1979; Muralidharan et al 1985; James et al 1987; Sreedharan and James 1988; Sampath et al 1989). While daily rainfall data are quite useful for such studies, the distribution in shorter intervals of time is important in many fields. The data from recording rain gauges show that rainfall is often confined to a few hours a day, and sometimes even for periods shorter than an hour. The period during which a given amount of rain occurs is important because heavier rainfall leads to greater runoff, greater soil erosion and less infiltration into the water table. A knowledge of rainfall intensity therefore becomes

Keywords. Rainfall intensity; Kerala; cumulative distribution. 
important from the point of view of better management of our dwindling fresh water resources and improved control of soil erosion.

This paper presents some of the first results from the measurement of rainfall intensity at a few stations in Kerala State. The measurements were done using a Joss-Waldvogel (1967) type disdrometer, an instrument for measuring rain drop size distribution (DSD). The instrument was installed at Thiruvananthapuram (lat. $8.29^{\circ} \mathrm{N}$, long. $76.59^{\circ} \mathrm{E}$ ), Kochi $\left(9.58^{\circ} \mathrm{N}, 76.17^{\circ} \mathrm{E}\right)$ and Munnar $\left(10.1^{\circ} \mathrm{N}\right.$, $77.1^{\circ} \mathrm{E}$ ) for varying durations. Of these, the first two are coastal stations and the third is on the Western Ghats at an altitude of about $1300 \mathrm{~m}$ amsl. (Preliminary results on drop size distribution were published in Sasi Kumar et al 2003). The disdrometer gives the number of drops that impact its sensor each minute in twenty different size classes, from which the rainfall intensity can be computed. The data from the disdrometer are compared with observations using a manual rain gauge.

\section{Comparison between disdrometer and manual rain gauge}

Daily rainfall was measured using a manual rain gauge at the site where the disdrometer was installed in Kochi and Thiruvananthapuram. These data were compared with the total rainfall computed from the rainfall intensity values obtained using the disdrometer, as a means of validating the disdrometer data. The data from the manual rain gauge represented the rainfall received between measurements on consecutive days. The disdrometer data corresponding to this period was taken for comparison. In general, we found that the total rainfall obtained from the manual rain gauge was less than that computed from the disdrometer data. Direct comparison was difficult because the disdrometer records data every minute, while manual data were recorded in the mornings of working days only. But the cumulative rainfall from both measurements show a more or less linear relationship, indicating that the values were more or less consistent, except for the under-estimation in the case of the manual rain gauge. Two examples for June and July 2005 are shown in figure 1.

When comparing the data from the manual rain gauge and the disdrometer, it is useful to note the following points. The disdrometer is a very sensitive instrument that detects even a single drop that falls on its sensor. Consequently, rainfall intensities as low as $0.001 \mathrm{~mm} / \mathrm{hr}$ are recorded. But there are certain factors that affect its measurement. The most important factor is that the disdrometer requires electric power, and hence, loss of power could lead to loss of data. Further, since the
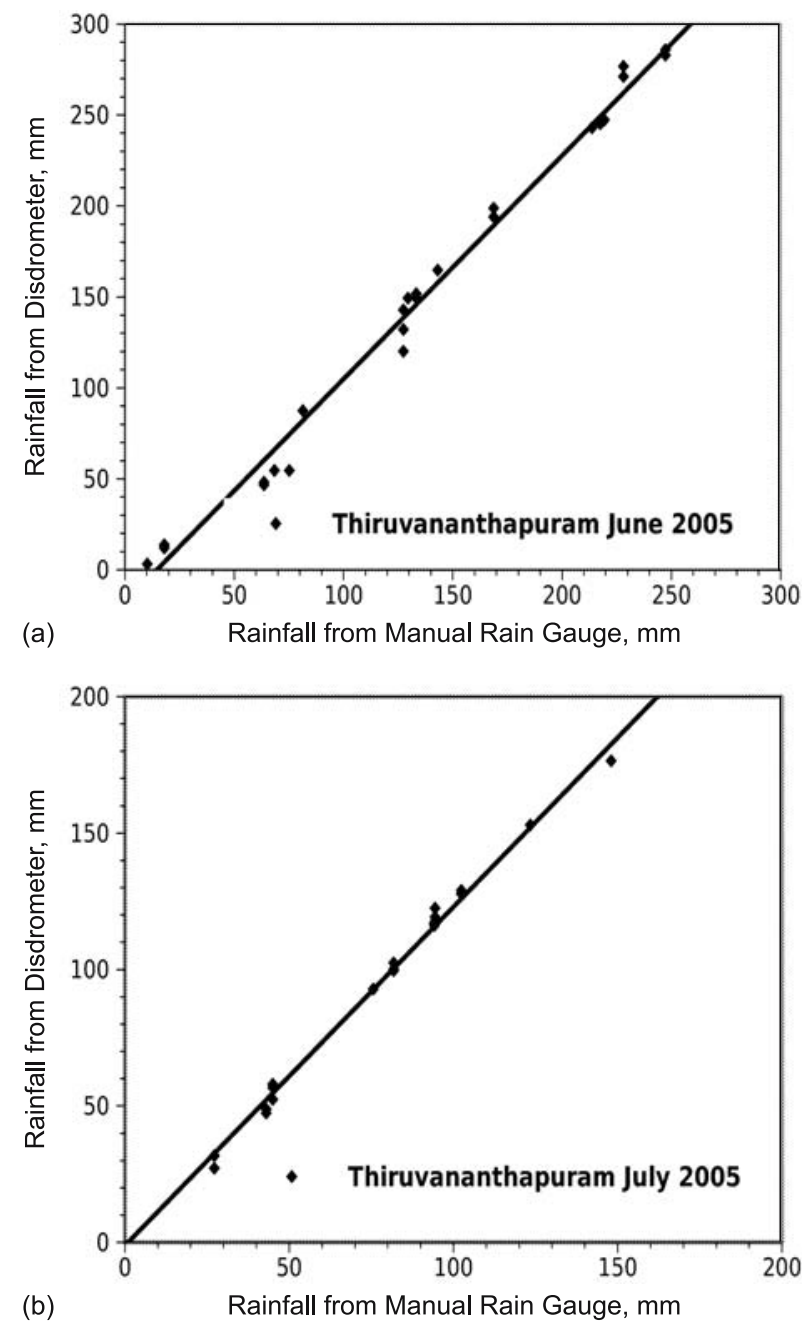

Figure 1. Comparison between rainfall data obtained from a manual rain gauge and a disdrometer.

disdrometer is sensitive only to raindrops of diameter greater than $0.3 \mathrm{~mm}$, the contribution from smaller drops to total rainfall, though small, is not accounted for. Similarly, since all drops larger than $5.3 \mathrm{~mm}$ fall into the same size class, there is a possibility that the mean drop size may be underestimated if very large drops are present, as could happen during heavy rain. All these would tend to reduce the total rainfall obtained from the disdrometer. Another possibility is that of raindrops splashing on the surface, and some of the droplets thus produced falling on the sensor. The company recommends keeping the sensor at the surface level to reduce the impact of winds that could produce spurious data. The sensor was, accordingly, kept at surface level at Thiruvananthapuram and Munnar. In Kochi, however, it was kept on a low stool, so that the possibility of rainwater splashing on the ground and falling on the sensor was virtually zero. Even in the case of rain water splashing onto the sensor, the drops would have speeds much below 
Table 1. Durations for which data from the three stations are presented in this paper and the highest intensity observed each month $(\mathrm{mm} / \mathrm{hr})$.

\begin{tabular}{rlrrr}
\hline No. & \multicolumn{1}{c}{ Station } & \multicolumn{1}{c}{ Month } & $\begin{array}{c}\text { No. of } \\
\text { minutes }\end{array}$ & $\begin{array}{c}\text { Highest } \\
\text { intensity }\end{array}$ \\
\hline 1. & Thiruvananthapuram & April 2001 & 193 & 140 \\
2. & & May 2001 & 154 & 46 \\
3. & & June 2001 & 1074 & 129 \\
4. & July 2001 & 1358 & 108 \\
5. & May 2005 & 1142 & 82 \\
6. & June 2005 & 1886 & 144 \\
7. & July 2005 & 5250 & 116 \\
8. & & August 2005 & 1695 & 94 \\
9. & Kochi & May 2002 & 912 & 171 \\
10. & & June 2002 & 5661 & 223 \\
11. & & July 2002 & 2612 & 107 \\
12. & & May 2004 & 1413 & 108 \\
13. & & June 2004 & 6632 & 102 \\
14. & Munnar & July 2004 (1-8) & 652 & 97 \\
15. & & July 2004 (9-31) & 10404 & 44 \\
16. & & August 2004 & 11880 & 61 \\
17. & & September 2004 & 11247 & 133 \\
18. & & October 2004 & 4171 & 46 \\
\hline
\end{tabular}

the terminal velocity, and hence their contribution cannot be large. On the other hand, there would be some loss of water from the manual rain gauge due to evaporation, as may happen when a generally sunny period is interspersed with light rainfall, and also due to the fact that the water in the container may not always be completely transferred to the measuring jar. In spite of taking into account all these factors, the discrepancy remains unexplained. The only possible reason for the discrepancy seems to be calibration errors. The manual rain gauge is certified by the India Meteorological Department, while the disdrometer is company calibrated.

For the time being, therefore, we leave this discrepancy unresolved. This may result in the intensity data presented here being higher by about $10-20 \%$ if the rainfall values from the disdrometer are later found to be higher than actual. However, the overall conclusions would not be significantly affected.

\section{Results}

Data used in this paper are for the periods as shown in table 1. The table also shows the number of minutes during which rainfall was measured in each month.

\subsection{Distribution of rainfall}

Table 1 shows that the duration for which rainfall was observed in the pre-monsoon months in
2001 at Thiruvananthapuram is very low, though in 2005 the duration of rainfall is longer. Rainfall during the pre-monsoon periods is scattered rather than widespread, and is mainly from cumulonimbus clouds. These clouds generally form in a region towards the east of the city and move in a generally westward direction. Our campus, where the instrument was situated, is at a location which is often missed by these clouds. In April 2001, for instance, there was only one rainfall event that gave heavy rainfall, when a cumulonimbus cloud passed almost overhead, and in May 2001, we received rainfall only on one day.

In Thiruvananthapuram, the month that has maximum duration of rainfall is July in both years (2001 and 2005). But in Kochi, the maximum duration of rainfall is seen to be in June in both years (2002 and 2004). The data are not sufficient to identify whether this is a normal feature. It is interesting to note that Munnar received rainfall almost $25 \%$ of the time in the months of August and September, which is much higher than that at the other stations. In July, the instrument was in Munnar only for twenty three days, but recorded rainfall for more than ten thousand minutes, which is about $31 \%$ of the time! This suggests that the maximum duration of rainfall may be in July in Munnar also. As we shall see, the rainfall was of very low intensity most of the time at Munnar. This is evident from the fact that the highest intensities observed in three of the four months the instrument was operated, there are comparatively low, being less than $50 \mathrm{~mm} / \mathrm{hr}$ in two months. 

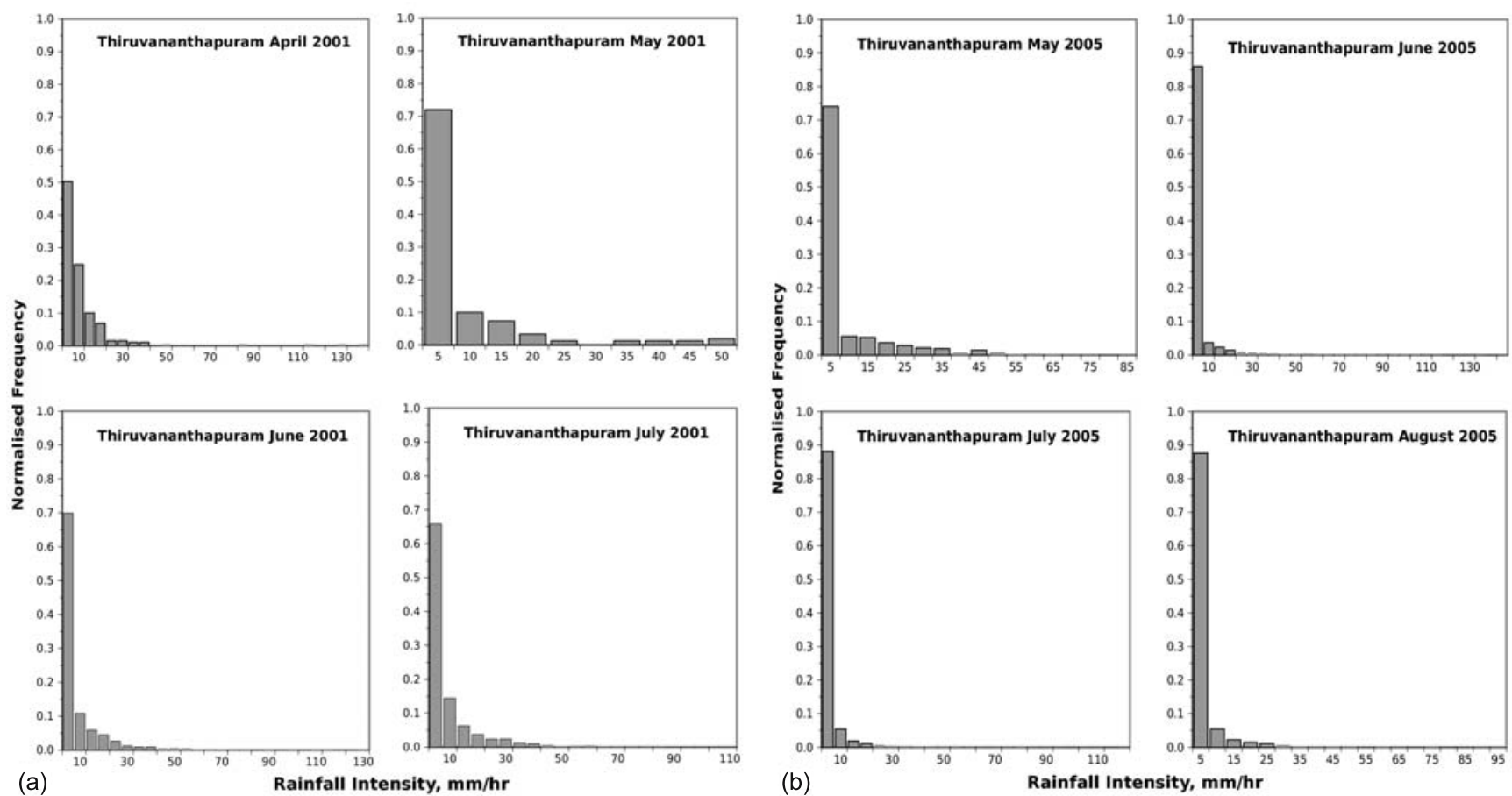

Figure 2. Rainfall intensity distribution at Thiruvananthapuram in (a) 2001 and (b) 2005. Note that the x scale is different in each graph because the maximum intensity observed is different.

\subsection{Temporal distribution of rainfall intensity}

We shall now examine the distribution of rainfall intensity with respect to time at the three stations. The results show differences in the distribution of rainfall intensity between stations, and between months at the same station. The rainfall intensity distribution at Thiruvananthapuram for four months in 2001 (from April to July) and in 2005 (May to August) is shown in figure 2. We see that the lowest intensity range $(0-5 \mathrm{~mm} / \mathrm{hr})$ dominates in all the months. This range has a probability of occurrence of $50 \%$ in April 2001, which is the lowest, and close to $75 \%$ in May 2001. This also indicates that the percentage of time rainfall is below $5 \mathrm{~mm} / \mathrm{hr}$, which is relevant in a state like Kerala which has a highly undulating terrain. However, since the data for these months is limited, the distribution seen here could very well be biased and not truly representative. In 2005, however, we find that the probability is more than $75 \%$ for rainfall below $5 \mathrm{~mm} / \mathrm{hr}$ in all the months, and in July it is almost $90 \%$, which is the highest for this station. Although the intensity range 0 to $5 \mathrm{~mm} / \mathrm{hr}$ dominates in all the months, the higher ranges are also seen prominently, especially up to about $50 \mathrm{~mm} / \mathrm{hr}$, in most of the months. Interestingly, the distribution does not show any striking difference between SW monsoon and pre-monsoon periods. We would normally have expected a greater share for higher intensity rainfall in May.

The frequency distribution of rainfall intensity for different months at Kochi is shown in figure 3. In all the months except July 2002, the probability of rainfall intensity being below $5 \mathrm{~mm} / \mathrm{hr}$ is $75-85 \%$. In July 2002, this is almost $95 \%$. In the other months, the intensity distribution is similar to that at Thiruvananthapuram in 2005. In July 2004 , the instrument was in Kochi for only 8 days, after which it was shifted to Munnar. The data thus is not for the entire month. The distribution is very similar in both years. Moreover, the highest intensity observed is in June $(223 \mathrm{~mm} / \mathrm{hr})$ though the next highest is in May $2002(171 \mathrm{~mm} / \mathrm{hr})$. These two are the highest intensities observed even when we consider all the stations and all the months. The year 2002 was a rainfall deficient year and the rainfall deficit was mainly in July. Our results appear to indicate a reduction in high intensity rainfall, which means a reduction in cumuliform clouds. It remains to be seen whether this could be the reason for lower rainfall in July 2002.

The distribution for Munnar (figure 4) shows that the probability of rainfall intensity being less than $5 \mathrm{~mm} / \mathrm{hr}$ is around $97.5 \%$ in July and October, and around 92\% in August and September. When we consider the fact that the highest intensities in July and October are around $50 \mathrm{~mm} / \mathrm{hr}$, and the highest intensity range 


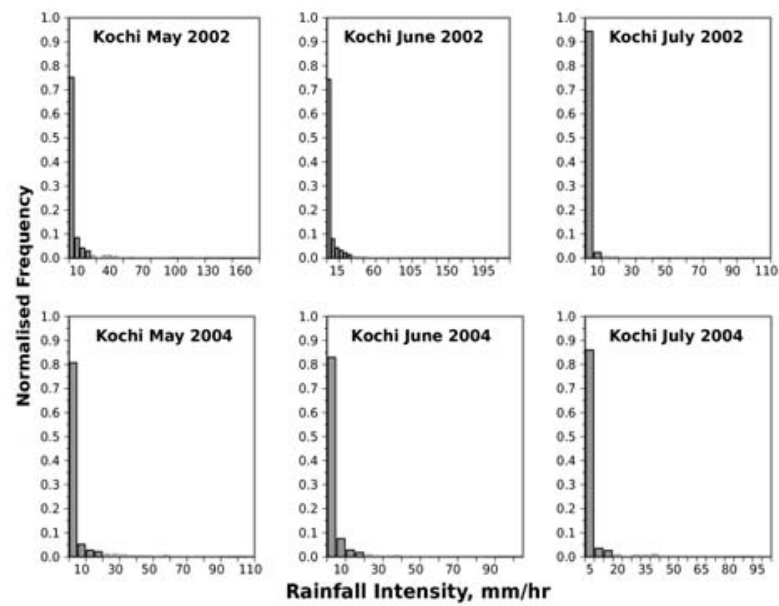

Figure 3. Frequency distribution of rainfall intensity at Kochi in three months each in 2002 and 2004.

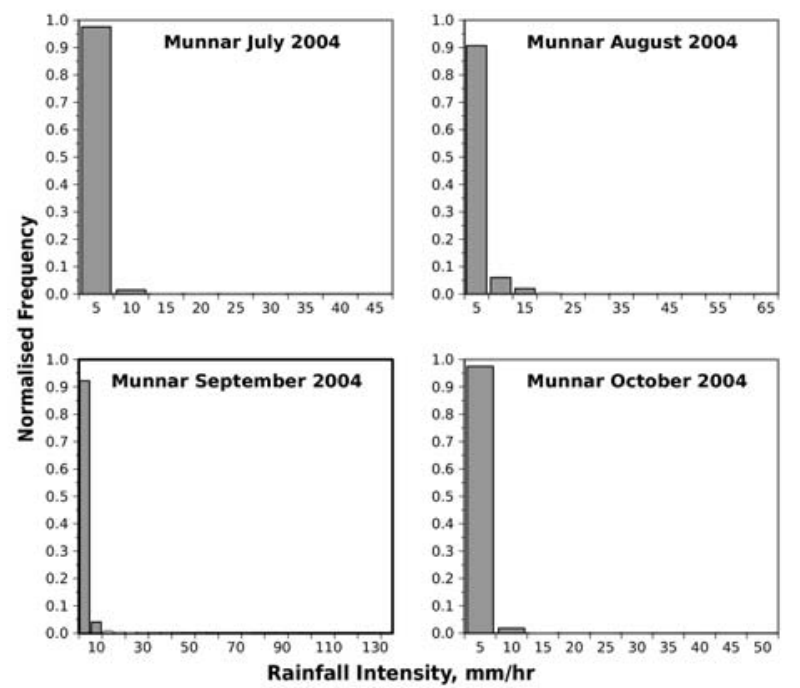

Figure 4. Frequency distribution of rainfall intensity at Munnar.

that had at least 5 minutes of rainfall was only $30 \mathrm{~mm} / \mathrm{hr}$, we see that rainfall intensities are very low during these months at Munnar. We have seen a somewhat similar distribution only in July 2002 at Kochi. There, the highest intensity recorded was $110 \mathrm{~mm} / \mathrm{hr}$, but that was only for one minute. The highest intensity recorded for more than five minutes at Kochi in July 2002 was only $40 \mathrm{~mm} / \mathrm{hr}$. The corresponding value for June 2004 was $57 \mathrm{~mm} / \mathrm{hr}$ and for June 2002 was $78 \mathrm{~mm} / \mathrm{hr}$. The limited data available for Munnar appears to show a different intensity distribution compared to the other two stations. The intensity distribution indicates that the rainfall in this region is predominantly from stratiform clouds, with cumuliform clouds being relatively rare. On the other hand, the intensity distributions at

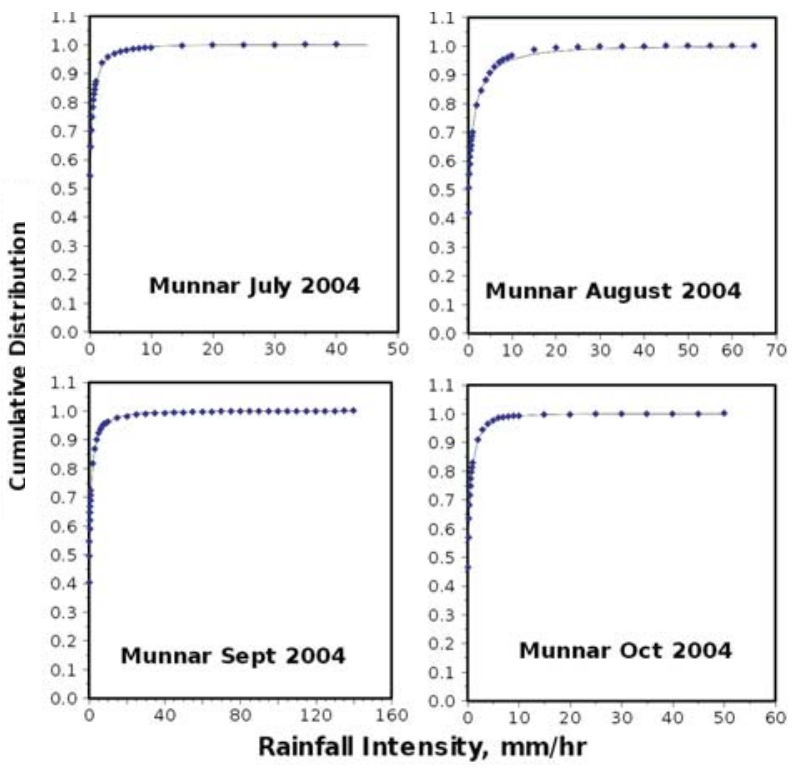

Figure 5. Cumulative frequency distribution of rainfall intensity at Munnar. The points represent measured values and the line represents the fitted Weibull distribution.

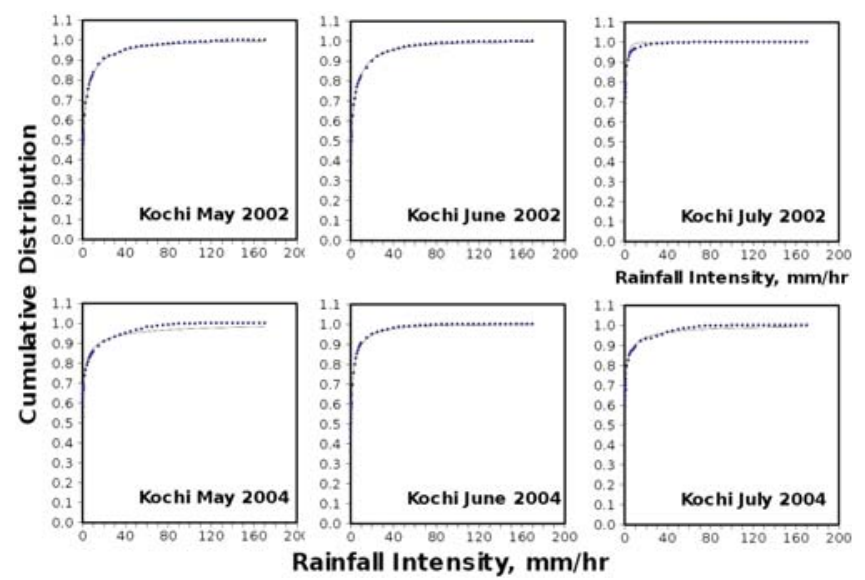

Figure 6. Cumulative frequency distribution of rainfall intensity at Kochi. The points represent measured values and the line represents the fitted Weibull distribution.

Thiruvananthapuram and Kochi show that cumuliform rainfall could be present during $10-20 \%$ of the time even during the SW monsoon period.

\subsection{Cumulative distribution of rainfall intensity}

The cumulative distribution, perhaps, shows the differences more clearly. The cumulative distribution for Munnar, Kochi and Thiruvananthapuram is shown in figures. 5, 6 and 7. The cumulative percentage was computed for values below $5 \mathrm{~mm} / \mathrm{hr}$ also because for $5 \mathrm{~mm} / \mathrm{hr}$ the percentage contribution is often around $80 \%$ and sometimes even $90 \%$ and higher. If only the points from $5 \mathrm{~mm} / \mathrm{hr}$ are plotted, most of the graphs would 

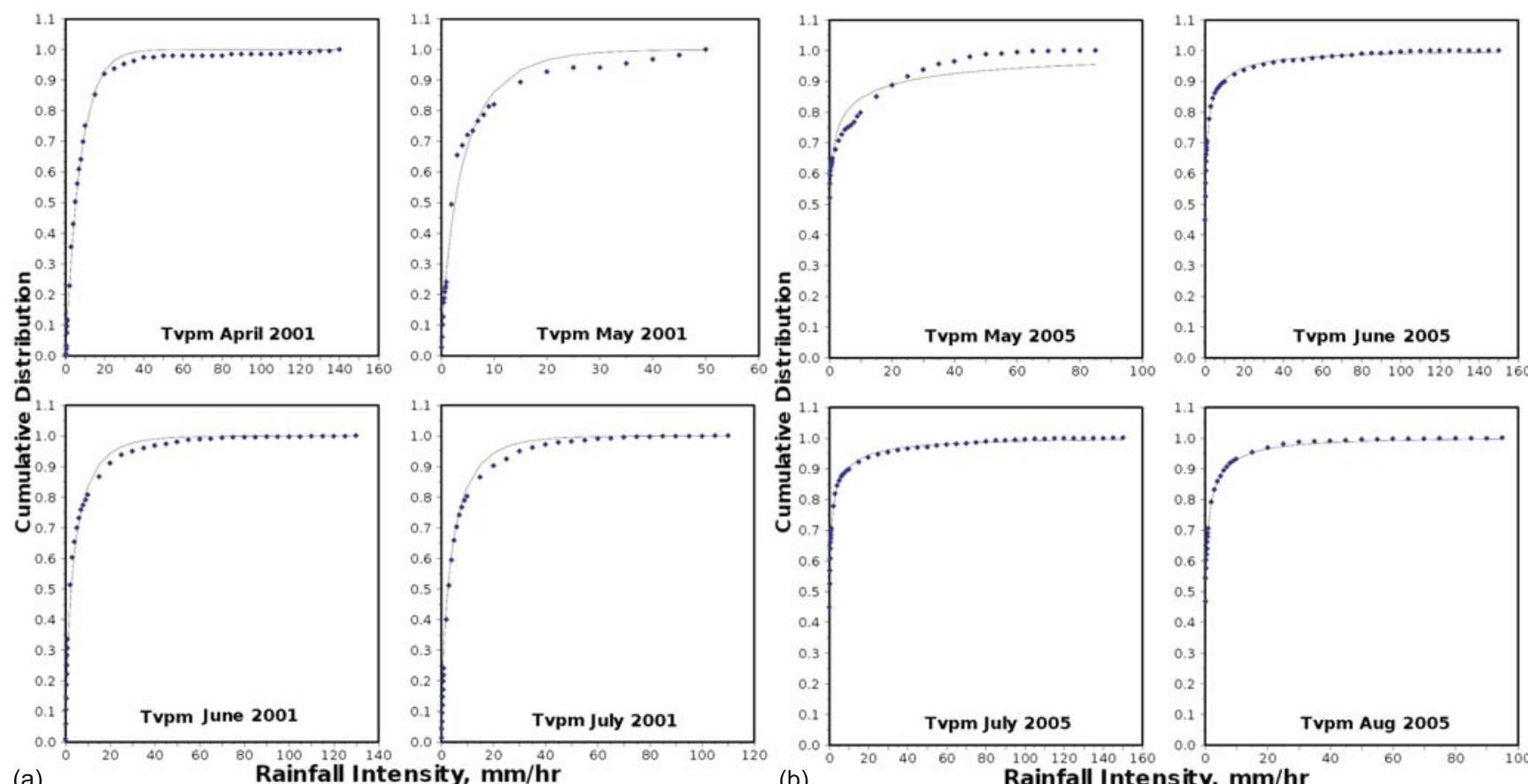

(a)

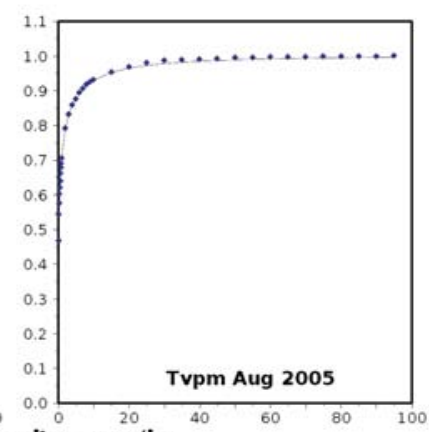

Figure 7. Cumulative frequency distribution of rainfall intensity at Thiruvananthapuram in (a) 2001 and (b) 2005 . The points represent measured values and the line represents the fitted Weibull distribution.

Table 2. Values of shape parameter, $k$ and scale parameter, $\lambda$ obtained when fitting the cumulative frequency distribution of rainfall intensity with the Weibull function.

\begin{tabular}{cllcc}
\hline No. & \multicolumn{1}{c}{ Station } & \multicolumn{1}{c}{ Month } & $k$ & $\lambda$ \\
\hline 1. & Thiruvananthapuram & April 2001 & $1.01 \pm 0.03$ & $7.52 \pm 0.14$ \\
2. & Thiruvananthapuram & May 2001 & $0.77 \pm 0.04$ & $4.12 \pm 0.19$ \\
3. & Thiruvananthapuram & June 2001 & $0.68 \pm 0.02$ & $4.22 \pm 0.14$ \\
4. & Thiruvananthapuram & July 2001 & $0.80 \pm 0.02$ & $5.08 \pm 0.13$ \\
5. & Thiruvananthapuram & May 2005 & $0.24 \pm 0.015$ & $0.73 \pm 0.10$ \\
6. & Thiruvananthapuram & June 2005 & $0.29 \pm 0.002$ & $0.51 \pm 0.01$ \\
7. & Thiruvananthapuram & July 2005 & $0.34 \pm 0.003$ & $0.51 \pm 0.01$ \\
8. & Thiruvananthapuram & August 2005 & $0.33 \pm 0.004$ & $0.51 \pm 0.01$ \\
9. & Kochi & May 2002 & $0.37 \pm 0.003$ & $2.03 \pm 0.02$ \\
10. & Kochi & June 2002 & $0.39 \pm 0.006$ & $2.27 \pm 0.05$ \\
11. & Kochi & July 2002 & $0.51 \pm 0.03$ & $0.42 \pm 0.02$ \\
12. & Kochi & May 2004 & $0.22 \pm 0.004$ & $0.44 \pm 0.02$ \\
13. & Kochi & June 2004 & $0.37 \pm 0.004$ & $1.08 \pm 0.02$ \\
14. & Kochi & July 2004 & $0.25 \pm 0.004$ & $0.37 \pm 0.01$ \\
15. & Munnar & July 2004 & $0.41 \pm 0.004$ & $0.18 \pm 0.002$ \\
16. & Munnar & August 2004 & $0.39 \pm 0.007$ & $0.56 \pm 0.01$ \\
17. & Munnar & September 2004 & $0.41 \pm 0.003$ & $0.54 \pm 0.005$ \\
18. & Munnar & October 2004 & $0.45 \pm 0.003$ & $0.29 \pm 0.001$ \\
\hline
\end{tabular}

not show the rising part of the curve. Beyond about $40 \mathrm{~mm} / \mathrm{hr}$, the graph is almost parallel to the $\mathrm{x}$ axis. In the case of Munnar, especially for July and October, the graphs rise almost vertically up to about $80-90 \%$ and then become almost horizontal. In the case of Kochi, except for July 2002, the higher intensities are clearly seen to contribute to a positive slope for the horizontal part of the graph.

The cumulative distribution graphs for Thiruvananthapuram (figure 7), on the other hand, are very different from these. In order to quantify 

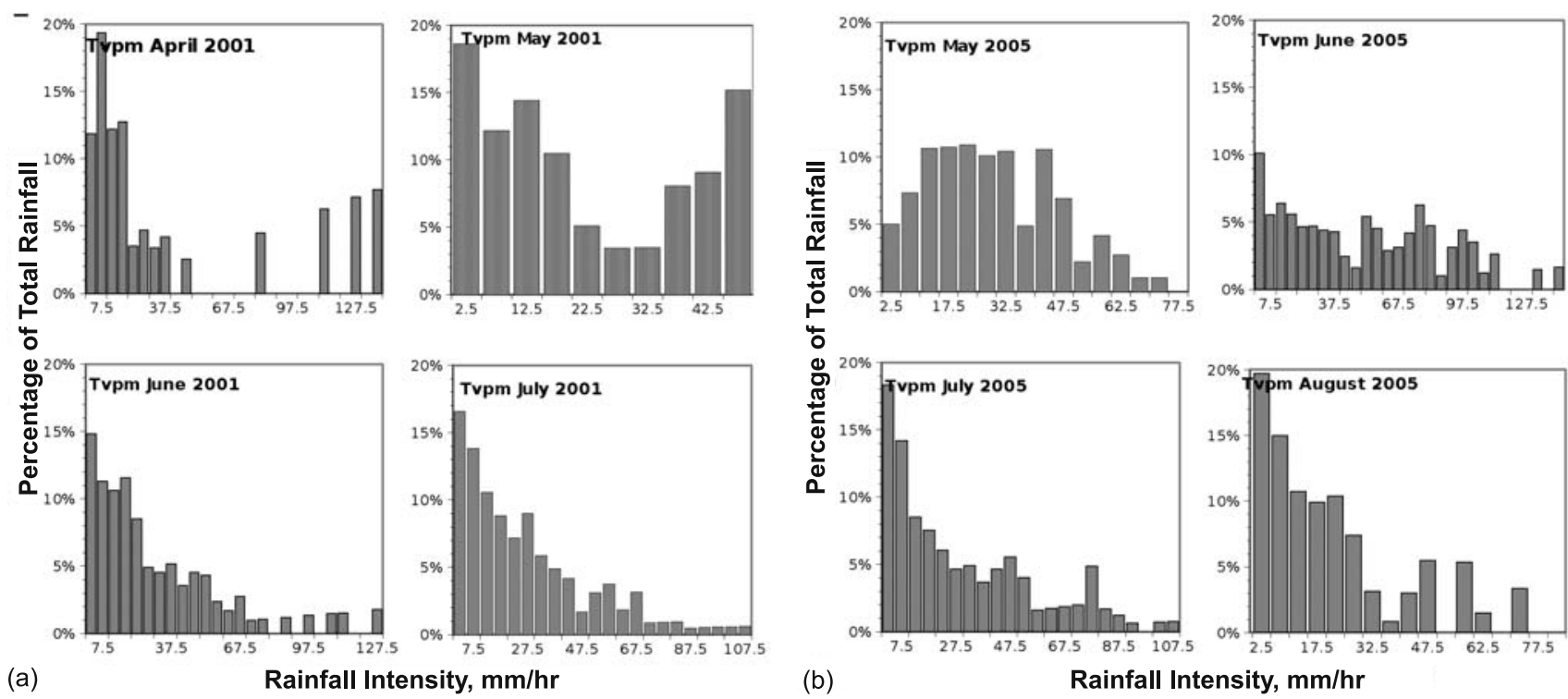

Figure 8. Histogram of the contribution of each intensity range to total rainfall at Thiruvananthapuram in (a) 2001 and (b) 2005 .

the differences, the cumulative frequency graphs were fitted with the Weibull function

$$
y=1-\exp \left(-(x / \lambda)^{k}\right)
$$

where $k$ is known as the shape parameter and $\lambda$ is known as the scale parameter of the distribution. Gnuplot, a free software for plotting graphs, was used for curve fitting. Gnuplot uses the Marquardt-Levenberg algorithm for non-linear curve fitting, which is known to give very good results for a wide variety of datasets. The fitted curves are shown in the figures, along with the observed values. The fit is very good in most cases, the exceptions being the data for the month of May in both 2001 and 2005 .

The fit parameters $k$ and $\lambda$ for all the months are given in table 2 . What strikes one when observing the table is the high values for both $k$ and $\lambda$ for Thiruvananthapuram in the year 2001. In both cases, they are the highest, and quite different from the values for the same station for the year 2005. (A higher value of $k$ indicates a more gradual increase, a more rounded curve, and a lower value indicates a sharper curve. A higher value of $\lambda$ generally means a higher $y$ value for a given $x$ value.) The reasons for this difference are not clear, and more measurements may be needed to understand these variations. A similar, but much smaller, difference can be seen between the data for the two years at Kochi. The values of $k$ and $\lambda$ in May and June 2002 are similar and higher than those in 2004, except for the value of $k$ in June 2004. But July 2002, a rainfall deficient month, is different, with a higher value of $k$ and a much lower value of $\lambda$. Interestingly, we do not see any difference between the values for pre-monsoon and monsoon months. Both at Thiruvananthapuram and Kochi, the values of $k$ and $\lambda$ during the pre-monsoon months are close to the values in the monsoon months. The only exception, if it can be considered so, is in the values of $\lambda$ at Thiruvananthapuram during the pre-monsoon months, which appear to be slightly higher than in the monsoon months. $\lambda$ has the lowest value for July in Munnar, and the second lowest in October. The values of $k$ at Munnar are all close together, unlike in any other case. Possibly by accident, $\lambda$ has the same value for the three months June-August 2005. Overall, the values of $k$ and $\lambda$ do not appear to have any consistent pattern at these sites.

\subsection{Contribution to total rainfall}

We shall now look at the contribution of each intensity range to total rainfall. We divided the observed rainfall intensities into ranges of $5 \mathrm{~mm} / \mathrm{hr}$ interval and computed the amount of rainfall obtained in each range. This was plotted as a percentage of the total rainfall, and also as the cumulative percentage. The scale of the y axis has been kept the same in all graphs to facilitate comparison (except in some cases, as pointed out later). The results are given below.

The graphs for Thiruvananthapuram are shown in figure 8. What strikes one immediately on seeing these graphs is their large difference from the distribution graphs of rainfall intensity with time for Thiruvananthapuram (figure 2). Unlike the latter, these graphs show that the higher intensities do contribute significantly to the total rainfall, 


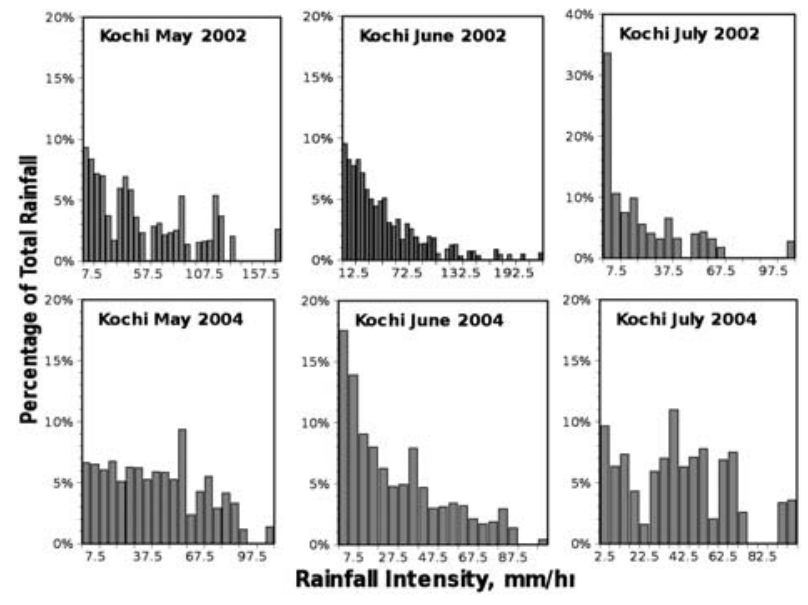

Figure 9. Histogram of the contribution of each intensity range to total rainfall at Kochi in 2002 (top) and 2004.

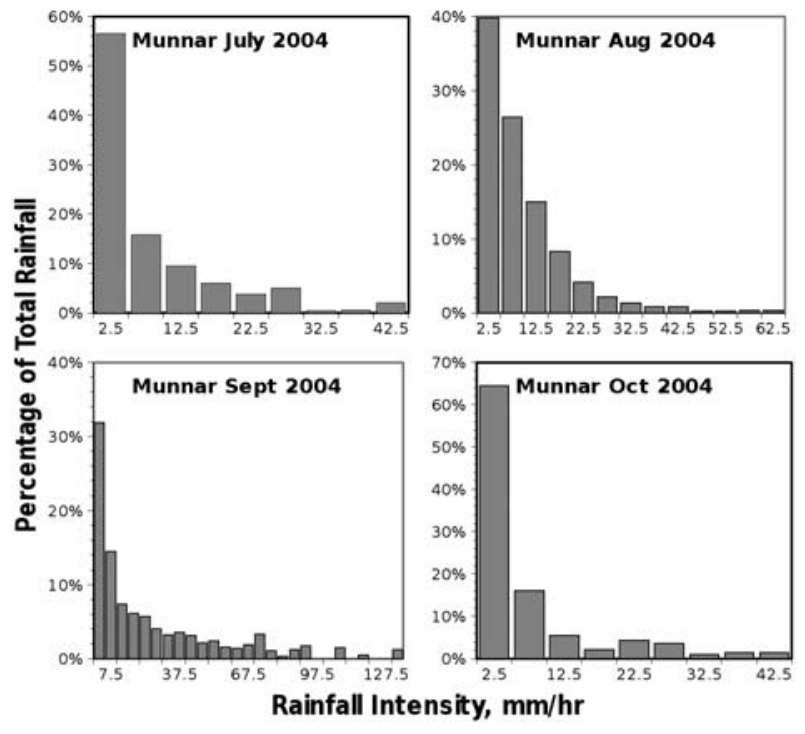

Figure 10. Histogram of the contribution of each intensity range to total rainfall at Munnar in 2004.

especially in the pre-monsoon months. During the pre-monsoon months in 2001, in fact, the lowest and highest intensities have contributed more than the middle ranges in the pre-monsoon months. However, the total rainfall received in these months is low, which could be one of the reasons why the occasional short duration heavy rain becomes important. But in May 2005, interestingly, the middle intensities contribute more than the lowest and highest. During the southwest monsoon period, the contribution is highest from the lowest intensity range in all cases, and the contribution decreases with increasing intensity. The only exception is June 2005, when the distribution is almost flat.

The distribution at Kochi during the months of May, June and July in 2002 and 2004 are shown in figure 9. Here also we see that all intensities contribute almost similarly during the pre-monsoon period, but the contribution decreases with increasing intensity during the monsoon months - the only exception being July 2004. Another point to note is that the scale of the $y$ axis is different for July 2002 , in which month the contribution from the lowest intensity range is very high. We had earlier found that rainfall during this month was less than $5 \mathrm{~mm} / \mathrm{hr}$ for about $95 \%$ of the time, leading us to suspect that the reason for rainfall deficiency in the month was the lower presence of cumuliform clouds. The present finding tends to confirm this suspicion.

Munnar (figure 10) presents a different picture. The low intensities are prominent here, with the range $0-5 \mathrm{~mm} / \mathrm{hr}$ contributing more than $30 \%$ in all months, and going up to $65 \%$ in October and more than 55\% in July. In August, even the range $5-10 \mathrm{~mm} / \mathrm{hr}$ has contributed more than $25 \%$, which is not seen at either of the other two stations in any month. It may be pointed out that the y scale is different in each of these graphs.

The cumulative contributions from the different intensity ranges to the total rainfall at the three stations are given in figures 11, 12 and 13. Unlike the cumulative distributions shown earlier, most of these curves do not appear to follow any well-defined pattern. The graph for May 2001 for Thiruvananthapuram, for example, is almost a straight line, and so are those for May and June 2005 to an extent. The graphs for May and July 2004 for Kochi also show an almost linear increase except for small departures. In view of this, no attempt was made to fit any function to the data.

\section{Discussion}

Ananthakrishnan et al (1979), after analysing hourly rainfall data for the monsoon seasons of 1969 and 1970, found that "falls of intensity $\geq 10 \mathrm{~mm} / \mathrm{hr}$ account for $14 \%$ of the rainfall at Thiruvananthapuram in less than $2 \%$ of the rain hours". What we find in the present study is that rainfall of intensity $\geq 10 \mathrm{~mm} / \mathrm{hr}$ is present during $19.25 \%$ of the time in June 2001, $19.8 \%$ in July $2001,10.23 \%$ in June 2005, $6.4 \%$ in July 2005 and $6.9 \%$ in August 2005. It accounted for $73.9 \%$, $69.6 \%, 84.3 \%, 67.5 \%$ and $65.3 \%$ of the total rain in these months respectively. This is very different from what they found. They continue to state that "Such falls account for about a third of the rainfall at stations from Cochin to Goa and 40 to 50\% at Vengurla and Bombay." In our study, we found that, in Kochi, rainfall of intensity $\geq 10 \mathrm{~mm} / \mathrm{hr}$ is present during $17.7 \%, 3.3 \%, 9.5 \%$ and $10.4 \%$ of the time in June 2002, July 2002, June 2004 and 

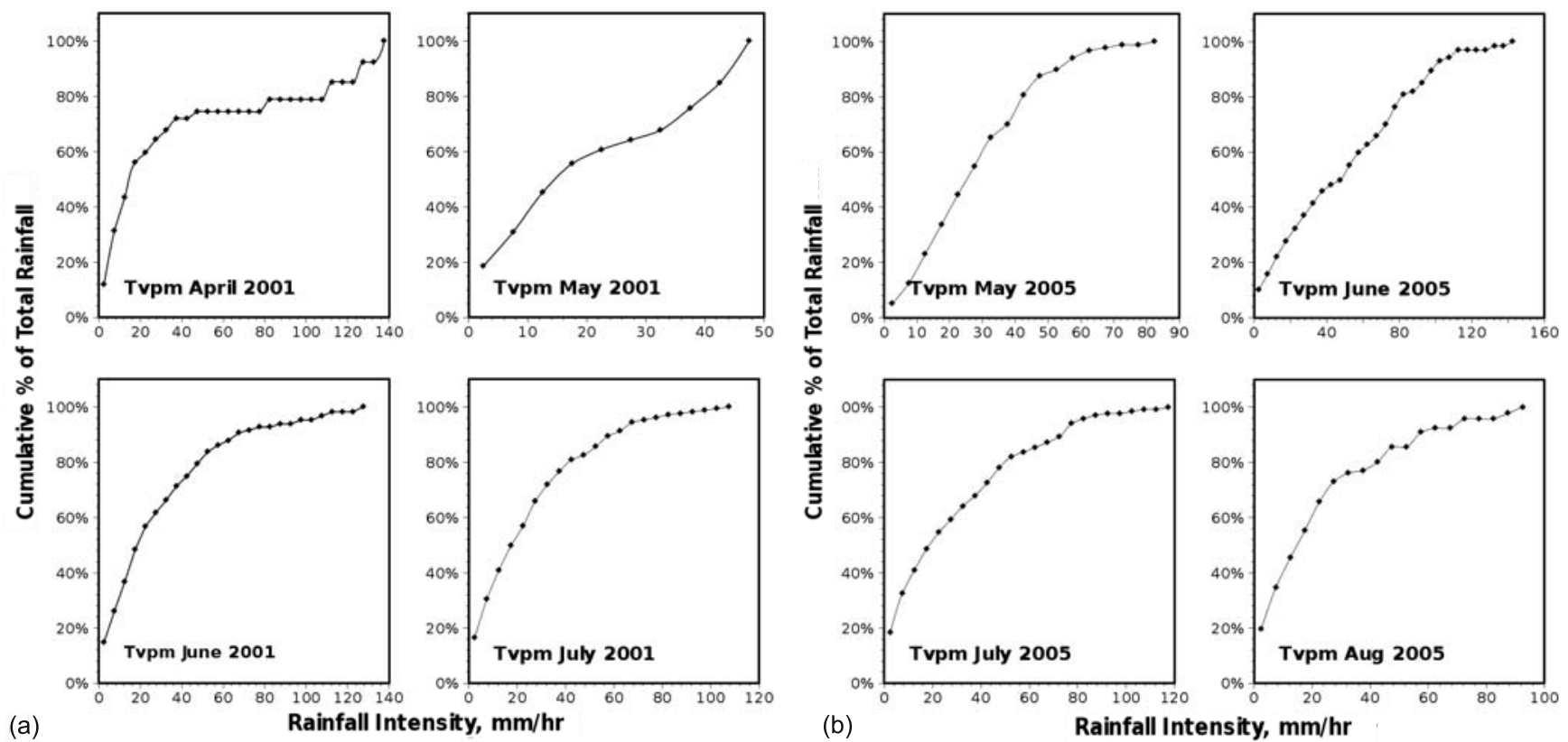

(b)

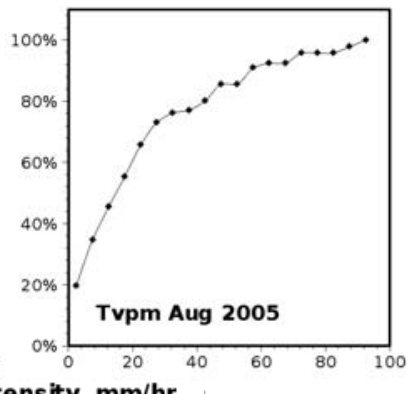

Figure 11. Cumulative contribution from each intensity range to total rainfall at Thiruvananthapuram in (a) 2001 and (b) 2005

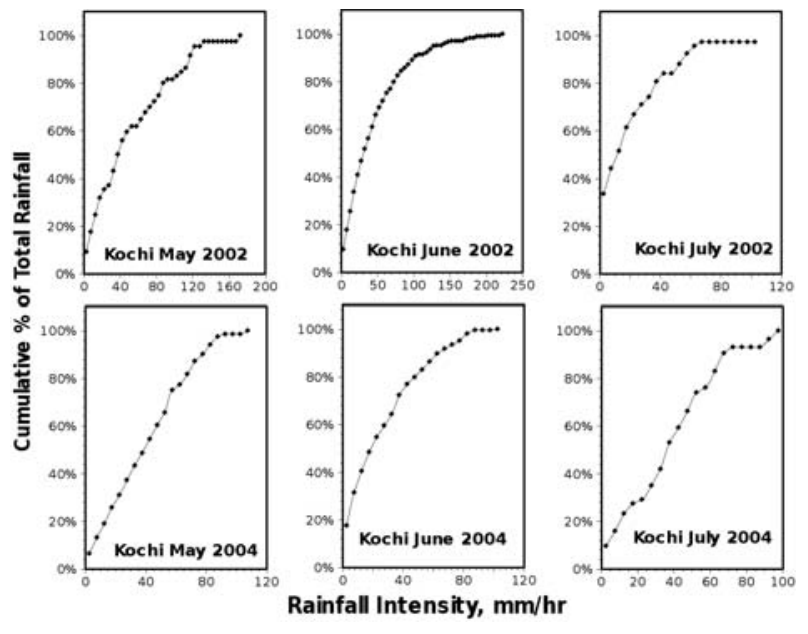

Figure 12. Cumulative contribution from each intensity range to total rainfall at Kochi in 2002 and 2004.

July 2004, respectively, and contributed $82.2 \%$, $54.8 \%, 68.6 \%$ and $84 \%$, respectively, of the total rainfall. These are not very different from the values for Thiruvananthapuram. This difference between these two studies needs to be explained. This is possibly a result of Ananthakrishnan et al using the hourly rainfall value in place of intensity, in the absence of intensity measurements. A rainfall of $1 \mathrm{~mm}$ depth that lasted for one minute would be counted as a $1 \mathrm{~mm} / \mathrm{hr}$ rain event, while, in fact, the intensity should be taken as $60 \mathrm{~mm} / \mathrm{hr}$. Thus, the intensity values used by Ananthakrishnan et al could be highly underestimated. This problem would also have affected the other conclusions they

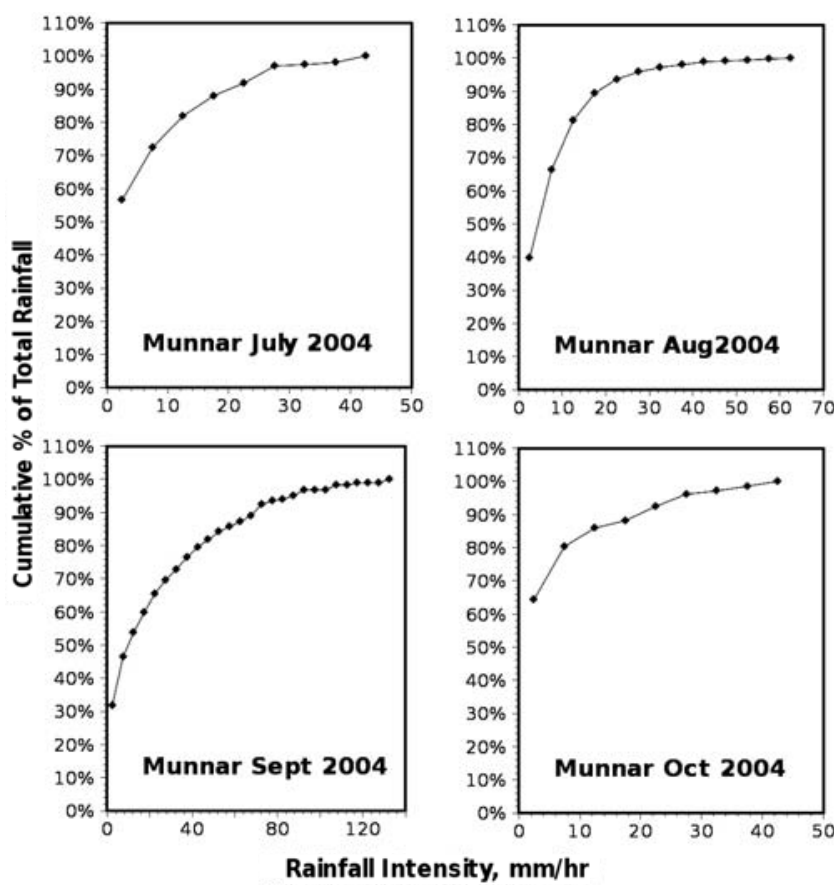

Figure 13. Cumulative contribution from each intensity range to total rainfall at Munnar in 2004.

have drawn, and is certainly the reason why their data do not show intensities greater than about $30 \mathrm{~mm} / \mathrm{hr}$.

Rainfall can be from stratiform or cumuliform clouds. The former is the dominant cloud form during the south-west monsoon season. They are generally expected to produce only light rainfall, while 
Table 3. The relative duration for which rainfall is below $20 \mathrm{~mm} / \mathrm{hr}$ and the contribution from this to the total rainfall.

\begin{tabular}{cllcc}
\hline No. & \multicolumn{1}{c}{ Station } & \multicolumn{1}{c}{ Month } & $\begin{array}{c}\text { Normalised } \\
\text { frequency }\end{array}$ & $\begin{array}{c}\text { Percentage } \\
\text { of total } \\
\text { rainfall }\end{array}$ \\
\hline 1. & Thiruvananthapuram & April 2001 & 92.1 & 56.1 \\
2. & Thiruvananthapuram & May 2001 & 92.7 & 55.7 \\
3. & Thiruvananthapuram & June 2001 & 91.1 & 48.3 \\
4. & Thiruvananthapuram & July 2001 & 90.1 & 49.8 \\
5. & Thiruvananthapuram & May 2005 & 88.6 & 33.8 \\
6. & Thiruvananthapuram & June 2005 & 93.6 & 27.7 \\
7. & Thiruvananthapuram & July 2005 & 96.6 & 48.6 \\
8. & Thiruvananthapuram & August 2005 & 96.8 & 55.3 \\
9. & Kochi & May 2002 & 90.9 & 31.8 \\
10. & Kochi & June 2002 & 90.0 & 33.8 \\
11. & Kochi & July 2002 & 98.5 & 61.5 \\
12. & Kochi & May 2004 & 90.7 & 25.9 \\
13. & Kochi & June 2004 & 95.1 & 48.5 \\
14. & Kochi & July 2004 & 93.3 & 27.6 \\
15. & Munnar & July 2004 & 99.7 & 88.0 \\
16. & Munnar & August 2004 & 99.4 & 89.5 \\
17. & Munnar & September 2004 & 98.1 & 59.9 \\
18. & Munnar & October 2004 & 99.7 & 88.2 \\
\hline
\end{tabular}

cumuliform clouds, especially cumulonimbus, can produce heavy rainfall. If we assume that a certain rainfall intensity is the maximum that stratiform clouds can produce, then we can roughly determine from the graphs given earlier the relative prevalence of these two cloud types in a given month. We need to keep in mind the fact that cumuliform clouds could produce light rainfall, though stratiform clouds cannot produce heavy showers.

Rain from stratiform clouds is often classified as slight, moderate or heavy if the intensity is $<0.5 \mathrm{~mm} / \mathrm{hr}$, between 0.5 and $4 \mathrm{~mm} / \mathrm{hr}$ and $>4 \mathrm{~mm} / \mathrm{hr}$. Rainfall from cumuliform clouds is said to be slight if it is $<2 \mathrm{~mm} / \mathrm{hr}$, moderate if it is between 2 and $10 \mathrm{~mm} / \mathrm{hr}$, heavy if it is between 10 and $50 \mathrm{~mm} / \mathrm{hr}$ and violent if it is $>50 \mathrm{~mm} / \mathrm{hr}$. These are values corresponding to the Beaufort letters used for recording weather. We assume the maximum rainfall intensity produced by stratiform clouds as $20 \mathrm{~mm} / \mathrm{hr}$. This is not based on any study of stratiform cloud properties or rainfall, but is an arbitrary value. The maximum intensity observed in any month in these measurements is at least $44 \mathrm{~mm} / \mathrm{hr}$ (at Munnar in July). What we have chosen is less than half this intensity. However, we need to remember that all rainfall of intensity less than this is not necessarily produced by stratiform clouds, and there would be some contribution from cumuliform clouds also. On the basis of this assumption, we find that rainfall is from stratiform clouds at least $88 \%$ of the time. At Thiruvananthapuram, rainfall is below $20 \mathrm{~mm} / \mathrm{hr}$ from 88.62 to 98.61 per cent of the time during the months the measurements were made. This rainfall contributes from $28 \%$ to $56 \%$ of the total rainfall for the month. No consistent difference between pre-monsoon and southwest monsoon months is seen. The values for the different stations for the different months are summarised in table 3 .

The table shows the predominance of low intensity rainfall in Munnar. Rainfall is below $20 \mathrm{~mm} / \mathrm{hr}$ more than $99 \%$ of the time in three of the four months, contributing at least $88 \%$ of the total rainfall. In September, though the rainfall was below $20 \mathrm{~mm} / \mathrm{hr}$ more than $98 \%$ of the time, it contributed only about $60 \%$ of the total rainfall for that month. This, and the fact that the maximum intensity observed in that month $(132.6 \mathrm{~mm} / \mathrm{hr})$ is much higher than in the other months indicate the greater presence of cumuliform clouds in this month. The reason for this is not clear.

Another interesting point is the dominance of low intensity rainfall in July 2002 at Kochi. Rainfall below $20 \mathrm{~mm} / \mathrm{hr}$ is present almost $99 \%$ of the time in July 2002, compared to around 90\% of the time in the other months (except in June 2004, when it is 95\%). Moreover, this has contributed about $62 \%$ of the total monthly rainfall in July 2002 while the highest in all the 

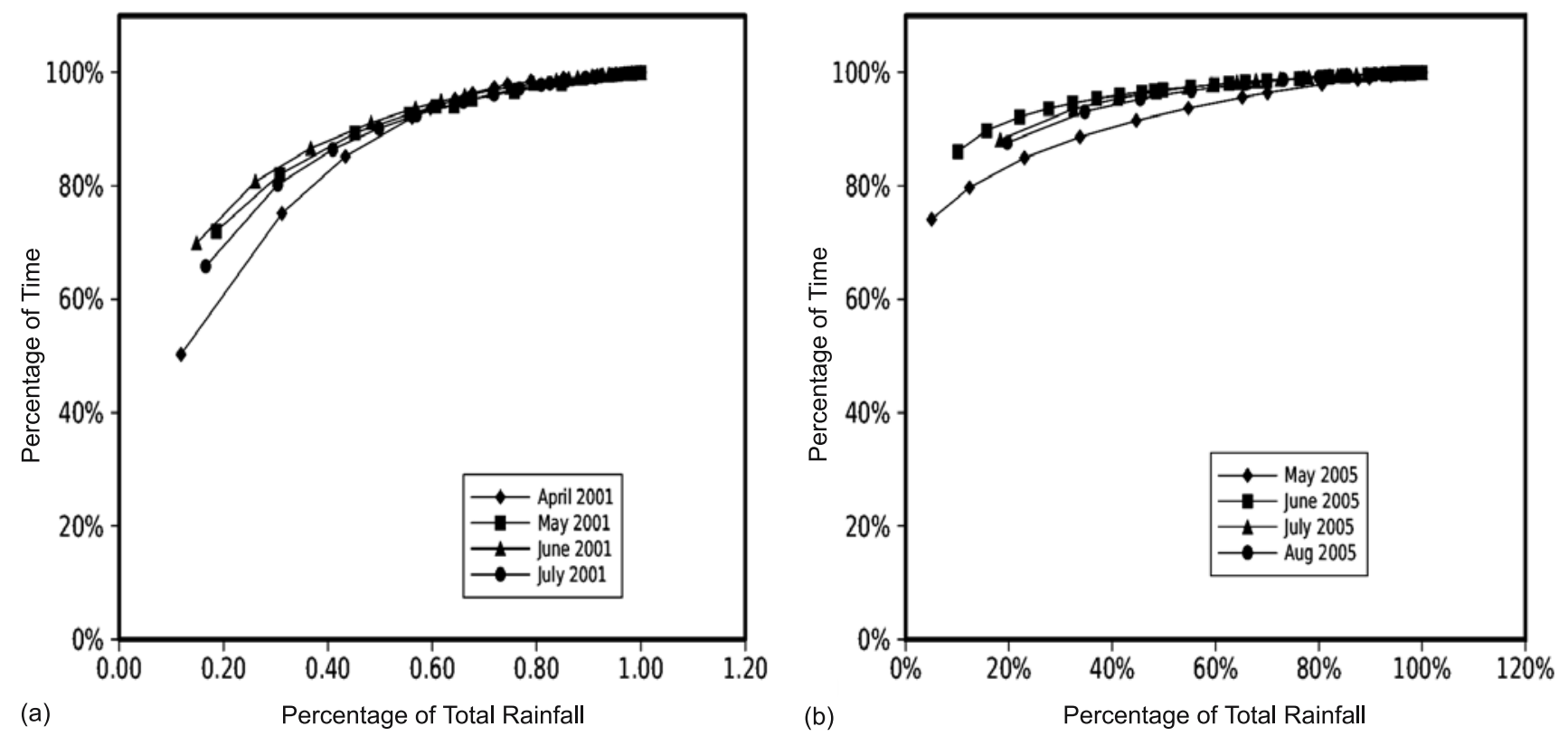

Figure 14. Variation of total rainfall with time at Thiruvananthapuram in (a) 2001 and (b) 2005.
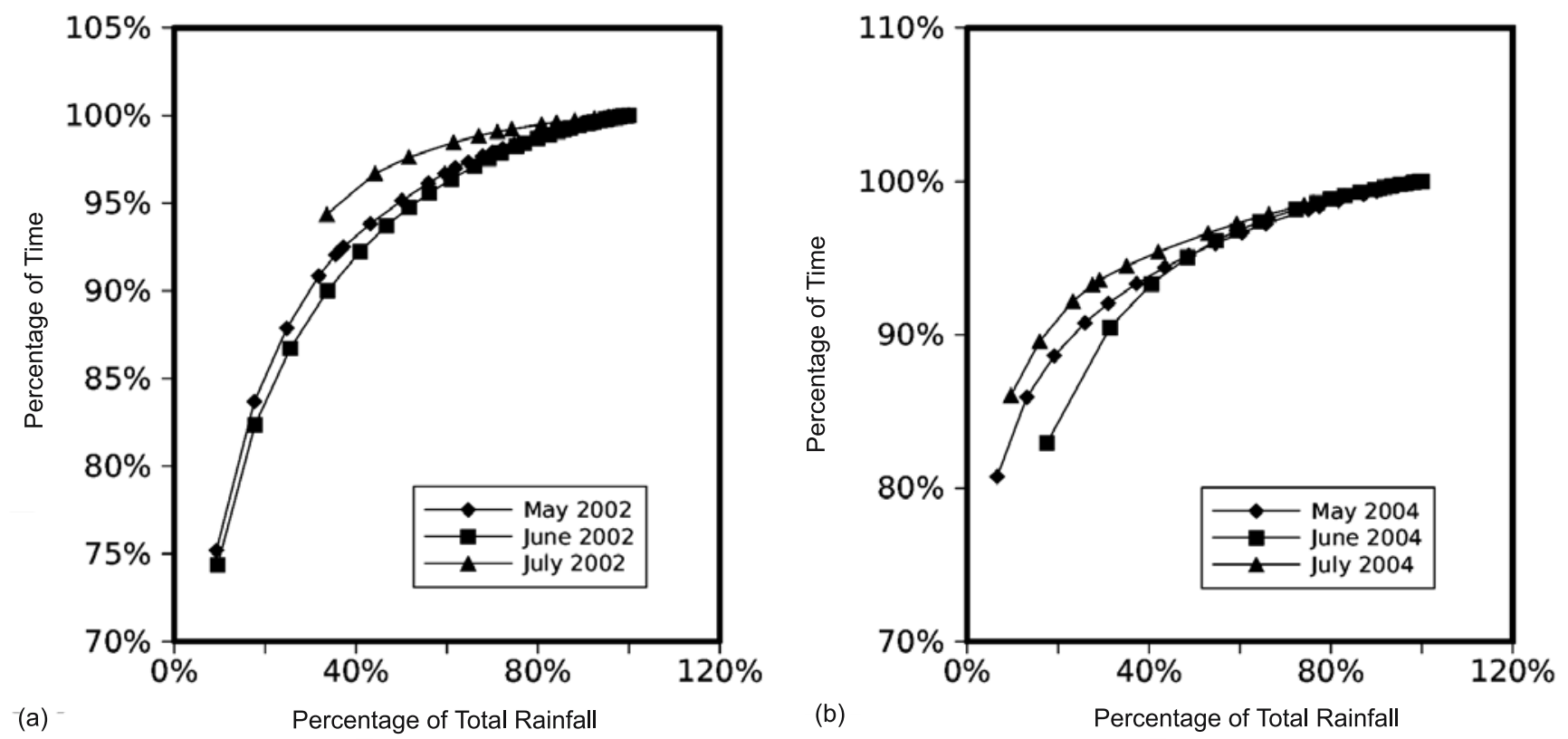

Figure 15. Variation of total rainfall with time at Kochi in (a) 2002 and (b) 2004.

other months is only less than $49 \%$. These figures strengthen our suspicion that the deficiency in rainfall was due to reduced presence of cumuliform clouds.

There does not appear to be any consistent difference between pre-monsoon and southwest monsoon months. But there are some interesting points that can be noted. The table shows that low intensity rainfall was present for more time and contributed more to the total rainfall in April and May, 2001, compared to June and July, at
Thiruvananthapuram. In 2005, the percentages are less in May, compared to the monsoon months. However, it is interesting that in June 2005, though low intensity rainfall was present almost $94 \%$ of the time, it contributed only less than $28 \%$ of the total rainfall (which is less than that for May 2005). The highest rainfall intensity observed at Thiruvananthapuram is in this month. This possibly indicates the presence of a small number of very active cumuliform clouds that gave short duration very heavy rainfall. 


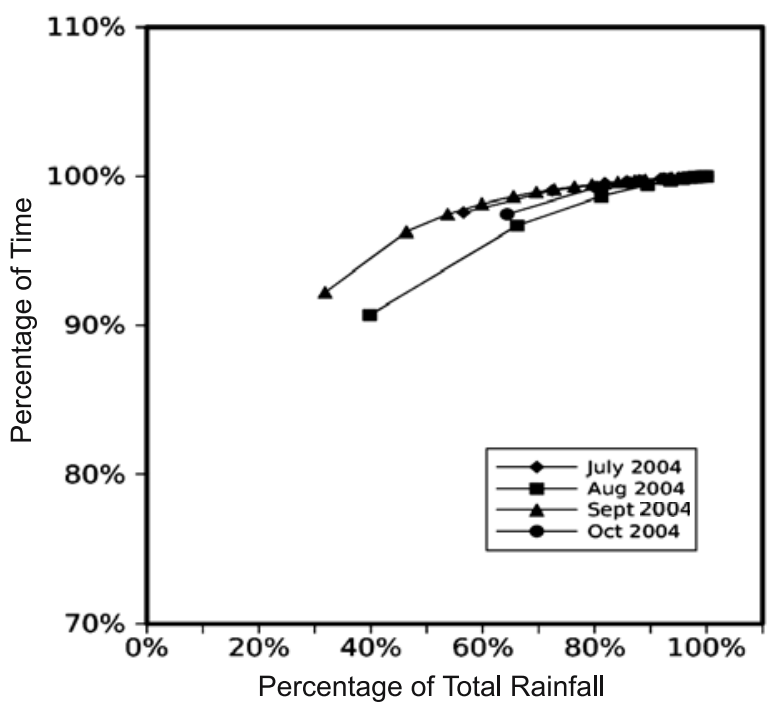

Figure 16. Variation of total rainfall with time at Munnar.

In order to understand the distribution of rainfall with time, we plotted the normalised frequency against the percentage of total rainfall for all months for each station. The graphs are shown in figures 14, 15 and 16 . We see that, at Thiruvananthapuram in June 2001, about $70 \%$ of the rainfall occurred in about $15 \%$ of the time and $90 \%$ in less than $50 \%$ of the time. In June 2005, however, about $90 \%$ of the rainfall was obtained in less than $20 \%$ of the time! In Kochi, around $90 \%$ of the rainfall was obtained in around $40 \%$ of the time in the year 2002, while in $2004,80-90 \%$ of the rainfall was received in about $20 \%$ of the time. It may be noted that the distribution is more or less similar in both June and July 2002, although we had seen some differences between these two months in our earlier analysis. In Munnar, the behaviour is very similar in all the months, but is very different from that at the other stations.

This information is very important for water conservation and management. The state of Kerala being a narrow strip of land with the Western Ghats on one side, rain water flows rapidly to the Arabian Sea. The short duration heavy rainfall tends to aggravate the loss of water and the related loss of top soil.

\section{Conclusion}

This paper presents the first study of variation of rainfall intensity at high time resolution conducted in Kerala. Though the measurements have been conducted only at three stations for durations of a few months at each station, the data give some insight into the behaviour of rainfall in this region, and also indicates the cloud types that may be present during different seasons. The high altitude station Munnar showed some peculiarities in the distribution of rainfall intensity, but no special feature could be seen for either Thiruvananthapuram or Kochi. The most interesting aspect was the apparently lower presence of cumuliform clouds during July 2002 at Kochi, which possibly contributed to the deficiency in rainfall.

Sampath and Vinayak (1989) found from their analysis of data from recording rain gauges at six stations in Kerala that the number of rainy hours in a year was only about 5 to 10 per cent of the total number of hours. This indicates the magnitude of the problem involved in the management of this resource. Measurements at one minute interval should give a still lower value since a rainy hour as recorded in the rain gauge need not necessarily mean that rain was present throughout the hour. We have not been able to run the instrument continuously throughout a year due to various reasons. But our results show that rainfall is present only for less than $10 \%$ of the time (or about 4300 minutes) even during a rainy month like June or July. This indicates that rainfall could be actually present only during $5 \%$ or less of the year.

\section{Acknowledgements}

The work reported in this paper was supported by the Department of Science and Technology, Govt. of India. We are thankful to Prof. P V Joseph, Emeritus Scientist, Cochin University of Science and Technology, for fruitful discussions and helpful suggestions. The authors acknowledge the assistance of Sri K P Bhaskaran (CESS Camp Office, Kochi), Sri T K Krishnachandran Nair and Sri M Mohammed Ismail in running the instrument and collecting data. The authors also thank $\mathrm{M} / \mathrm{s}$ Tata Tea Ltd. for permitting them to install the instrument in their premises at Munnar, and Sri Haridas, Dy. General Manager in charge of $\mathrm{R} \& \mathrm{D}$ for his interest in the work and the help rendered.

\section{References}

Ananthakrishnan R, Aralikatti S S and Pathan J M 1979 Some features of the southwest monsoon rainfall along the West Coast of India, Proc. Indian Acad. Sci. 88A 177-199.

Gordon H B, Whetton P H, Pittock A B, Fowler A M and Haylock M R 1992 Simulated changes in daily rainfall intensity due to the enhanced greenhouse effect: implications for extreme rainfall events; Climate Dynamics $\mathbf{8}$ 83-102. 
Haylock M R and Nicholls N 2000 Trends in extreme rainfall indices for an updated high quality data set for Australia, 1910-1998; Internat. J. Climatol. 20 1533-1541.

James E J, Saseendran S A, Chandrasekharan M E and Anitha A B 1987 Rainfall frequency studies for Kerala region; J. Inst. Engineers (India) 68(C) 74-81.

Joss J and Waldvogel A 1967 Ein Spektrograph fuer Niederschlagstropfen mit automatischer Auswertung; Pure Appl. Geophys. 68 240-246.

Muralidharan V, Kuriyan P P, Vinayak P V S S K and Sampath S 1985 A brief study of the orographic effect of Western Ghats on monsoon rainfall; Geogr. Rev. India $4732-37$.

Sampath S and Vinayak P V S S K 1989 Rainfall in Kerala; Report of the Centre for Earth Science Studies, Thiruvananthapuram.

Sasi Kumar V, Sampath S and Vinayak P V S S K 2003 Drop size distribution of rainfall of different intensities, Indian J. Radio Spa. Phys. 32 217-220.

Sreedharan K E and James E J 1988 A frequency study of rainfall for the Periyar basin of Kerala; Mausam 39 429-432. 